\title{
Improved Teaching Techniques in Technical Education
}

\author{
Moayyad Al-Nasra \\ Engineering Technology Department \\ West Virginia University Institute of Technology, Montgomery, WV 25136 \\ E-mail: Moayyad.alnasra@mail.wvu.edu
}

Received: May 20, 2012

Accepted: June 16, 2013 Published: August 1, 2013

doi:10.5296/jse.v3i3.3729

URL: http://dx.doi.org/10.5296/jse.v3i3.3729

\begin{abstract}
The main purpose of this study is to present a contemporary educational model that addresses the students concerns and coops with the new technological changes in the society. The model incorporates two types of courses, technical courses and non-technical courses. New approach called Active Learning Techniques (ALT) will also be presented. These techniques put the students in the center of the teaching and learning process, where students can assume calculated risk based on their performance in the class. Students can be rewarded by their classmates for excellent academic performance in a challenging and exciting way under well defined and unanimously approved rules at the beginning of the semester. This ALT is proved to be very effective for the weak and below average students. Results of class study will be presented.
\end{abstract}

Keywords: Technical education, Recitation, Active learning 


\section{Introduction}

There are four major issues instructors are facing everyday and still pose major challenge to the educational system; critical thinking, lack of concentration, ethics and communication skills. These issues are exacerbated by the new emerging technologies which became available to almost everyone including students. Educators are still struggling to take advantage of these emerging technologies and to utilize these technologies as effective tools in classrooms. Another approach addressing these issues is to understand the problems and the challenges the students are facing with the new emerging technologies. The teaching techniques should change accordingly in order to have better use of the allocated instructional time. Some of the recognized problems at technical schools can be summarized as follows:

(1) General weakness in math/science fundamentals;

(2) Relating math concepts to practical engineering problems;

(3) Low graduation rate;

(4) Wide range of students' backgrounds, students’ priorities, and even age groups;

(5) Teaching methods to keep students motivated.

One of the most important objectives of technical institutions is to provide sufficient number of quality engineering graduates economically and within reasonable time. Another goal is to prepare graduates for professional practice with good marketable skills in the competitive technical market. To accomplish some of the main objectives of the technical education, continuous evaluation of the curriculum will be needed. The technical educators usually prepare students to become productive professionals in the technical market, but, unfortunately, the technical market is moving at faster rate than the technical education. This ultimately puts pressure on the technical educators to improve courses and curriculums at a faster rate (Al-Nasra, 2012).

Pilotti et al (2013) examined whether retrieval practice promoting conceptual integration can improve test performance and self-assessment. Several tests were conducted on students' performance. These test showed during the first half of the semester, test performance was higher following practice focused on concepts than practice focused on conceptual integration. No difference existed during the second half. Performance was correlated with estimates before testing when practice emphasized individual concepts, but not conceptual integration.

Sikor et al (2012) studied different learning techniques among adult students in higher learning institutions. The study focused on the students' learning process by identifying dominant learning techniques. The study focused on students in the early adult age of 21 years old and older. The study was carried out qualitatively through the instruments of survey forms and supporting interviews. The main findings of the study show that the common problem usually faced by students is being too worried about the academic achievement which is dependent of the student age.

Chou and Kuo (2012) studied factors affecting the classroom attendance and performance. 
Their study examined the relationship between four class attitudinal variables and how it affects class attendance and performance. Statistical data were collected and analyzed in light of several variables under consideration. They concluded that the strongest predictor of success of a course is based on the student's level of attendance.

Recent study by the National Academy of Engineers (NAE, 2005; Mattis, 2005) identified the ideal attributes of the engineer of 2020, and recommended ways to improve the education and training of engineers to prepare them to the work effectively within the global market. The report recommended that the engineering educators and curriculum developers should anticipate and adopt the dramatic changes in the engineering market. Several engineering organizations have been active in addressing the challenges facing the new technical education in the context of the global competition. The Accreditation Board of Engineering and Technology (ABET) provided a set of well defined criteria called program outcomes that define levels of skills and knowledge a student must accomplish before graduation.

\section{Methodology}

This study includes mainly four engineering classes; Strength of Materials class of 23 students, Construction Project Management of 45 students, Engineering Mechanics section 1 of 22 students, and Engineering Mechanics section 2 of 21 students. The students are engineering students at different levels from junior to senior. Additional helping sessions were announced early in the semester, where students can ask questions about the lecture part and engage in discussions about particular issue or the class in general. These helping sessions are not mandatory, and the time of these sessions is selected to be convenient to students. The helping session is divided into three major parts. The first part is general review where the instructor reviews all what was covered during the week with additional numerical and/or non-numerical examples. The second part is general discussion. In this part the student can ask questions about the lecture part and elaborate on the examples covered. The third part is homework solution and discussion about the homework. In this part ALT can be used to improve the academic performance of the students as well as encourages students to attend the helping sessions.

\section{Recall Study}

Students like anybody else are bombarded with continuous flux of data and information in the classroom and outside the classroom. The easy and fast access to information and data added a burden on the students to sort out the continuous stream of data. This urges educator to change their teaching techniques focusing on helping students to sort the data and information given in the classroom, and making the presentation of new data and information uniquely different than any other source. This helps students to differentiate between a reliable and important sources, and non-reliable and random sources. One way to accomplish this goal is to give different level of emphasis on the material covered in the classroom. This can be accomplished by organizing recall sessions. During the recall session the material covered will be re-arranged based on its applicability, and importance. The techniques used in these recall sessions are dependent on the technical content of the processed data and information. Processing technical data is different than processing non-technical data. Figure 1 shows the 
effect of the recall session of a technical course, while Figure 2 shows the effect of the recall session of a non-technical course. These two figures show that the recall sessions are more effective for the technical courses compared to non-technical courses. In general, there is about $40 \%$ percent improvement in the students' academic performance in the technical courses compared twenty $22 \%$ in the non-technical courses.

Studies show that the student attendance and his/her active participation in the learning process is the main factor of improving the student academic performance. The number of activities students are carrying out daily nowadays is relatively higher than the number of activities carried out by students few years ago. The society is moving toward a more dynamic society when it comes to data processing and data exchange. This puts pressure on our students to prioritize their goals in life. Attending school regularly may seem to be number one priority a student should have for a parent paying for their kid to go to school, but it may not be the number one priory for that student. Missing a regular class becomes common event where student does have to justify skipping classes as used to be in the past, and missing a voluntary recall session is even more apparent nowadays. This phenomenon is associated with the many problems the society is facing nowadays. Changing majors, changing schools, dropping in the middle of the semester, and missing many classes are on the rise, at the same time the cost of education is on the rise too. Attending regular classes and attending recitation sessions are proven to be a major factor in improving the academic performance of the students, as shown in Figure 3, and Figure 4. Also Figure 3 shows that the " $A$ " students are attending the recitation session at approximately $82 \%$ rate compared to the "F" students who are attending the recitation sessions at approximately $3 \%$ rate for the technical base courses. Figure 4 shows slightly different percentages, but the same trend which is applied for non-technical base courses, where the "A" students are at $100 \%$ rate, and the "F" students are at $12 \%$ rate.

\section{Active Learning Techniques, ALT}

It is getting more difficult to keep the students of the new generation motivated compared to the previous generation. One of the most critical elements in teaching technical courses is to motivate students to be engaged in the classroom and participate in the teaching/learning process. Students' active participation creates a productive and creative learning environment. Teaching technical courses should be different from teaching non-technical courses. Group projects along with lectures and labs are proven to be very effective (Al-Nasra, 2012). The techniques are based on; encouraging team building skills, well defined evaluation systems approved by students, effective communication skills, and decision making process.

In the helping sessions, spare time "called team competition time- TCT" for the students to participate and take control of the teaching/learning process. The following points help manage the TCT more effectively:

- Set up rules to conduct the TCT and have the students vote on these rules, modify them, or create new rules at the beginning of the semester. These rules may include the time allowed for each team to solve a homework problem on the board successfully, penalties, incentives, switching groups, and the allowed idle time. 
- Assign homework problems and have students solve these problems on the board as teams. Try to make the number of the problems matches the number of teams in the class. Each team will be assigned to solve a problem on the board, which is randomly selected at the beginning of the TCT. The team should be prepared to solve all of the problems.

- Any team that solves and presents the problem correctly will gain a point. Any team that fails to do so will not gain a point, at the same time will not lose a point either.

- In case of a team failure to solve a problem, then the point that was not gained will be up for grab by any other team. The other team will compete to gain that point. Develop a procedure to select that team fairly and in a way acceptable and agreed upon by the whole class. If the other team solves and presents the earlier tried problem correctly, then that team will gain that point, otherwise that team will lose, in this case, a point and may go in the negative, and the only way to neutralize this lost point is by gaining a point in their turn. In case if no team is able or willing to solve this problem, then the instructor will step in and solve that problem for the class, and no point is gained.

- At the end of the semester, each team will accumulate points that will be translated into grades. Additional grades may be added to these grades by allowing each team member to evaluate other members of the same team based on criteria agreed upon by the whole class, which may include efforts, participation, absence points, and contribution.

This process shift the responsibilities toward the students, having them earn their grade and compete for it. At the same time this process helps students choose their team members carefully, and makes the students responsible not only for their grades also for their team grade, which turned to be good motivational technique. This encourages students to pay more attention to the class, and participate more effectively in the teaching/learning process putting the student in the center of this process. Also this process helps the weak student to catch up with the rest by putting efforts in the class in addition of establishing effective communication and team building skills.

Figure 5 shows the result of the study using ALT in Engineering Mechanics classes. The study used two sections of engineering mechanics classes in the same semester where 22 students were in the first section and 21 students were in the second section. ALT was utilized in the first section while the second section traditional teaching techniques were used. One can conclude from Figure 5 that there is a substantial improvement in the students' academic performance. Over $80 \%$ of students with ALT got a grade of C or better, compared to $39 \%$ of students without ALT.

\section{Conclusion}

New and effective model was presented, that showed improvement in the academic student performance. Teaching a technical class is different than teaching non-technical class, and the techniques used should be modified accordingly. The teaching/learning process should be constantly evaluated based on the ever changing variables affecting the educational process. Attendance is also a major factor that plays a significant role in defining the students' final grade. New and innovative techniques can make significant difference in students' academic 
performance.

\section{References}

Al-Nasra, M. (2012, November). Promoting Innovative Methods in Technology Education. US - China Education Review Journal A, 2, 965-970. Retrieved from http://www.davidpublishing.com/davidpublishing/Upfile/1/6/2013/2013010667726673.pdf.

Chou, P., \& Kuo, Y. (2012). Examining Factors Affecting Classroom Attendance and Performance. Journal of Studies in Education, 2(2), 193-204. http://dx.doi.org/10.5296/jse.v2i2.1564

Mattis, M., \& Sislin, J. (2005). Enhancing the Community College Pathway to Engineering Careers. National Academy of Engineering. The National Academies Press.

National Academy of Engineers. (2005). Educating the Engineers of 2020. The National Academies Press.

Pilotti, M., LaGrange, L., Martinez E., Mahamane, S., \& Almand, J. (2013). Is Learning Enhanced by Conceptual Integration During Practice. Journal of Studies in Education, 3(1), 1-10. http://dx.doi.org/10.5296/jse.v3i1.2441

Sikor, A., Ibrahim, A., Hashim, M., \& Madar, A. (2012). Learning Techniques among Adult Students in Higher Learning Institutions, Ministry of Higher Education Malaysia. Journal of Studies in Education, 2(4), 174-186. http://dx.doi.org/10.5296/jse.v2i4.2097

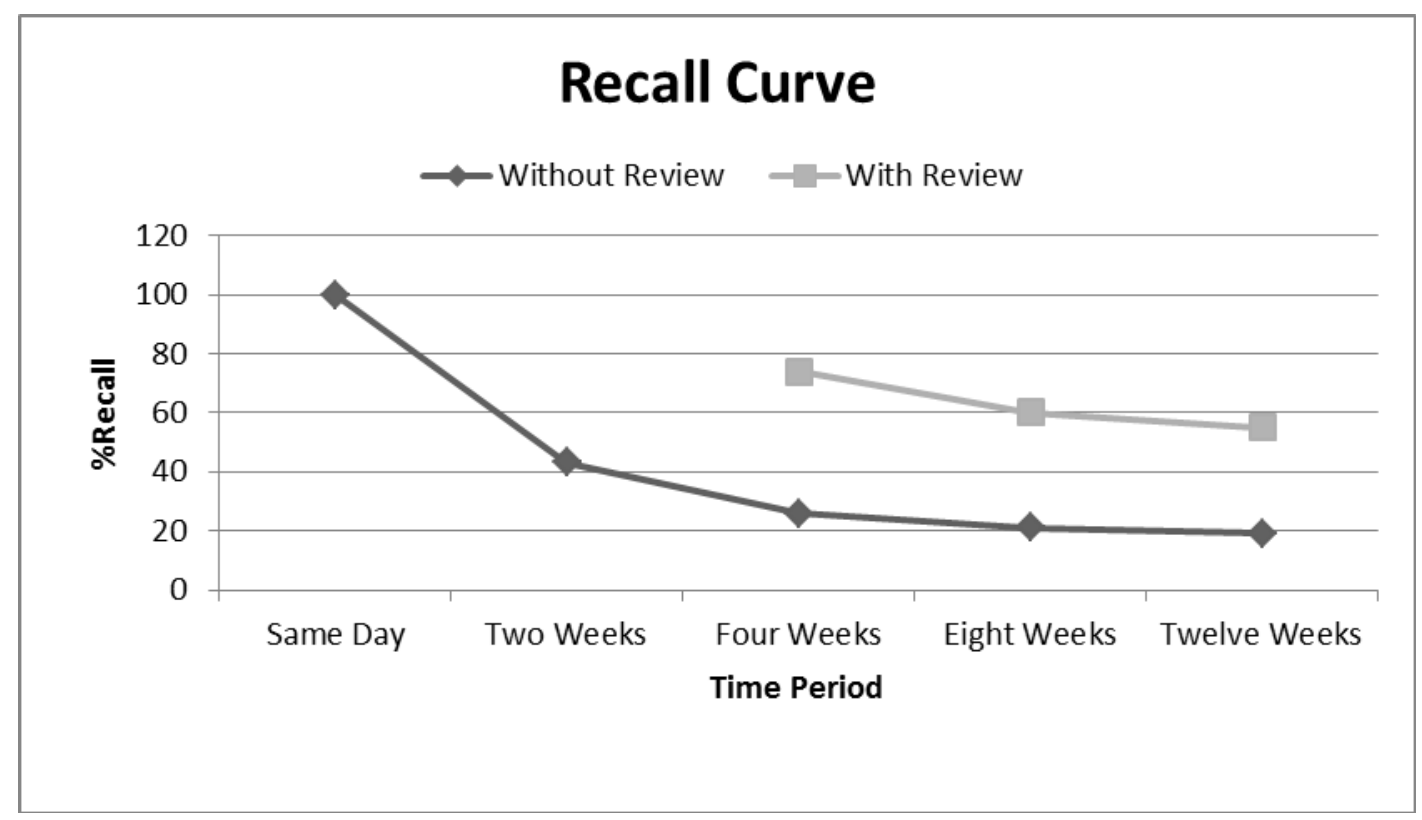

Figure 1. Effect of recitation on students' recall in technical base courses 


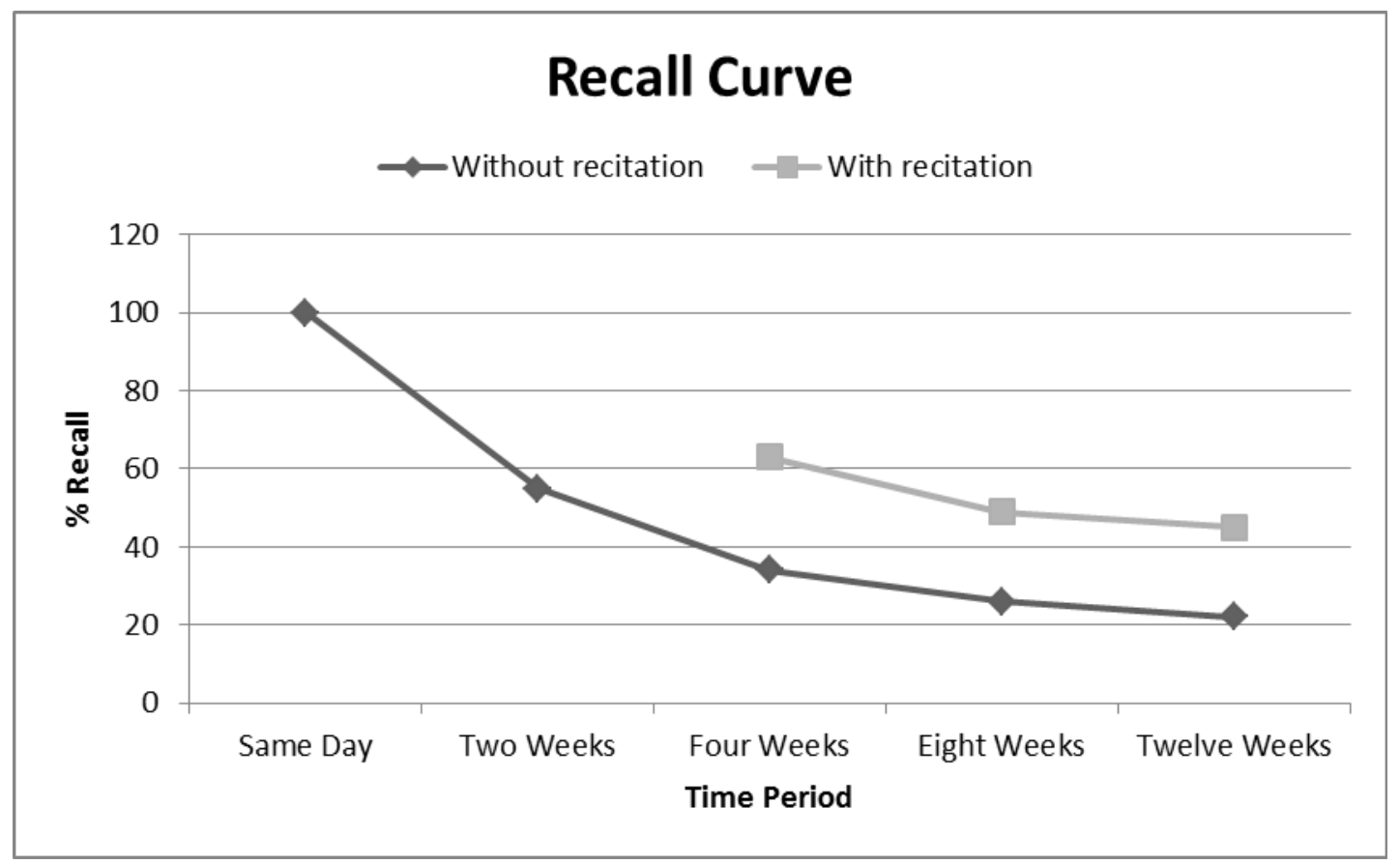

Figure 2. Effect of recitation on students' recall of memory base courses

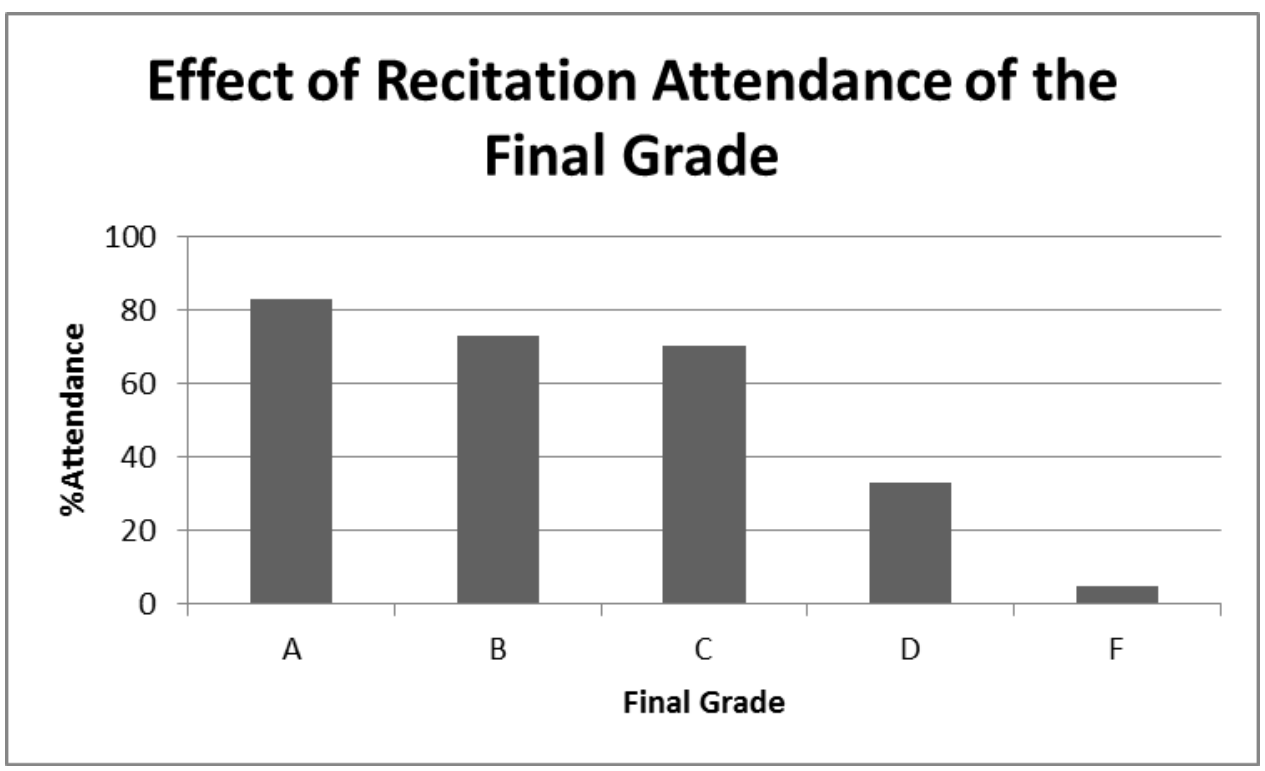

Figure 3. Effect of recitation on the final grade, technical base courses 


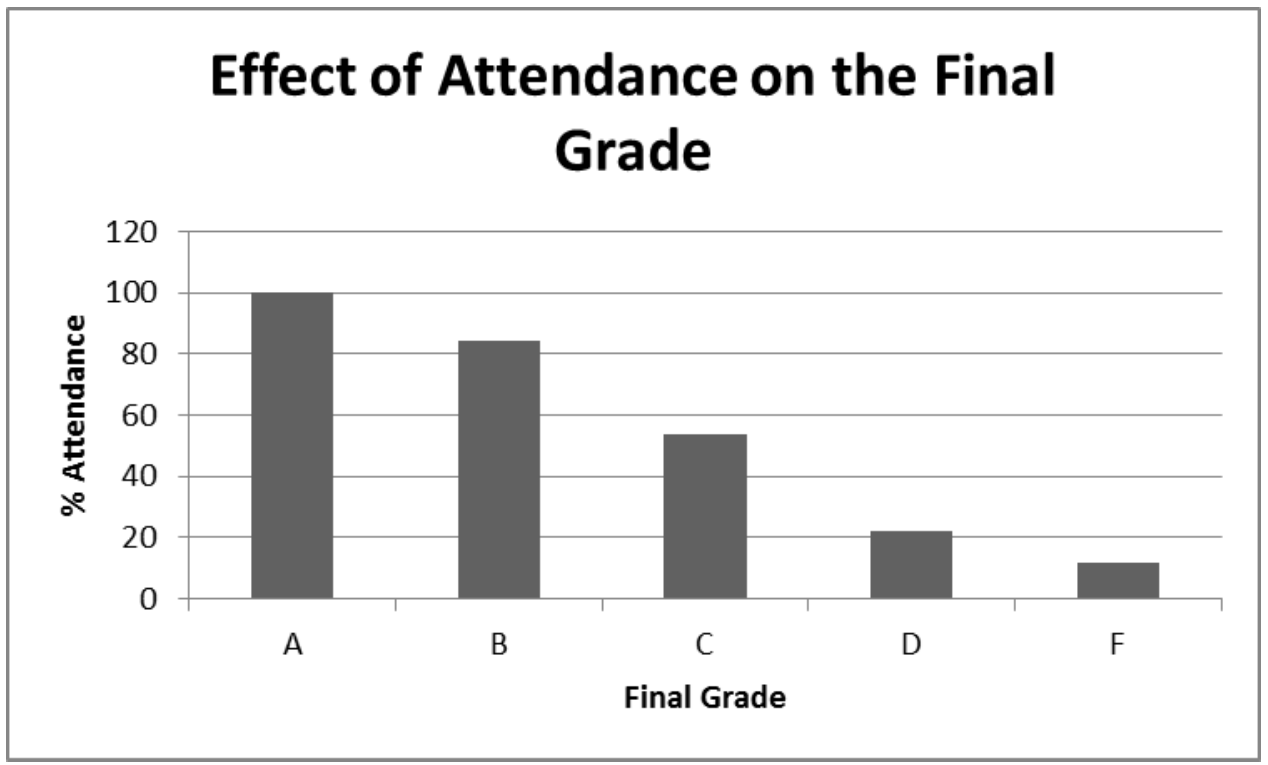

Figure 4. Effect of recitation on the final grade, non-technical base courses

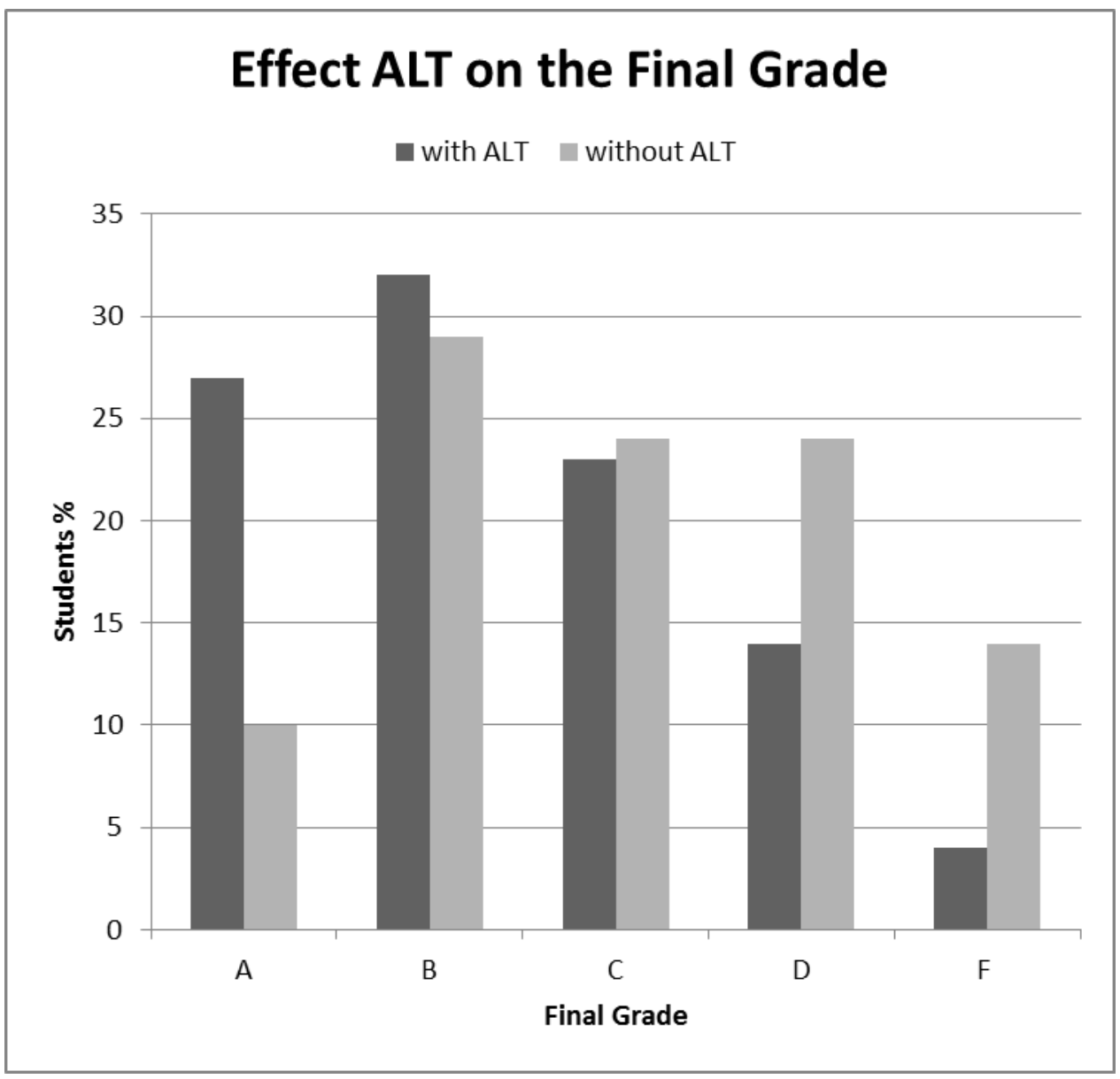

Figure 5. Effect of Active Learning Technique on students’ performance 